\title{
Smartphone Usage among Medical Students in Saudi Arabia
}

\author{
Mohammed Alhassan ${ }^{1}$, Abdullah Al Mulhim ${ }^{2}$, Saoud Sultan $^{3}$, Hayder Alnofaily $^{4}$, Murtada Alfayez ${ }^{5}$, \\ Hassan Alfarhan ${ }^{6}$, Hassan Busaleh ${ }^{7}$
}

Department of psychiatry, King Fahd University Hospital, Alkhober, KSA

\begin{abstract}
Introduction: This study was initiated to determine the psychometric properties of the Smart Phone Addiction Scale (SAS) by translating and validating this scale into the Arabic language (SAS-A), which is the main language spoken in Saudi Arabia and determining smartphone usage among medical students in one of the medical schools in Saudi Arabia. This study can distinguish smartphone and internet addiction among Saudi medical students. Furthermore, it has also demonstrated the reliability and validity of the SAS. Materials and Methods: A total of 243 participants were selected between July 2016 and October 2016 to complete a set of questionnaires, including the SAS and the modified Kimberly Young Internet addiction test (IAT) in the Arabic language. Results: There were 128 males and 115 females with ages ranging from 18-20 years, 21-23 years, more than 23 years included in this study. Descriptive and factor analyses, Chi-Square tests and correlation analyses were conducted to verify the reliability and validity of the SAS. The internal consistency and concurrent validity of the SAS-A were verified (Cronbach's alpha =0.917).Allof the subscales of the SAS-A were significantly related to the Arabic version of the IAT. Conclusions: The SAS-A showed good reliability and validity for the assessment of smartphone addiction. The smartphone addiction scale Arabic version, which was developed and validated in this study, used effectively for the evaluation of smartphone addiction among medical students in Saudi Arabia.
\end{abstract}

Keywords: Smartphones, Smartphone addiction, Internet addiction, Medical students, KSA

\section{Introduction}

The internet and smartphone were originally designed to facilitate communication and other activities. However, more recently communication technology appears to have overtaken our daily lives. Regardless of age, gender, ethnicity, career or economic status, and due to the large increase in the use of smartphones in recent years seem to have led considerable number of people to have become psychologically dependent on them. The term addiction does not only refer to substance abuse, but it also extended to others. the term 'addiction' when a person is obsessed with a certain activity that results in disturbance of his/her daily activities and showsa pattern similar to substance dependence. According to the survey of smartphone addiction completed by the National Information Society Agency in 2012, the percentage of smartphone addiction was $8.4 \%$, which was found to be higher than the internet addiction of $7.7 \%$. The higher figure in teenagers to individuals in their twenties than in those in their thirties to forties implies that this problem may worsen in the future. Similar to many other Western countries, in Switzerland, nearly all adolescents aged $12-19$ years (98\%) own a mobile phone, most of which (97\%) are smartphones (Medienpädagogischer Forschungsverbund Südwest, 2014; Willemse et al., 2014). While mobile applications offer several promising ways to prevent and treat chronic diseases such as diabetes (Arsand, Muzny, Bradway, Muzik \& Hartvigsen, 2015; Bain, Jones, O’Brian \& Lipman, 2015) or alcoholism (Gustafson et al., 2014), there are also obvious adverse effects on physical and mental health caused by their overuse. Examples of adverse physical effects include neck pain symptoms (Lee, Kang \& Shin, 2015) or accidents affecting pedestrians and drivers while the phone is used when the user is driving (Klauer et al., 2014; Shelton, Elliott, Lynn \& Exner, 2009). Regarding mental health, recent studies showed that increased smartphone use might be related to sleep disturbances and depression (Lemola, Perkinson-Gloor, Brand, Dewald-Kaufmann \& Grob, 2015). Furthermore, increasing frequency and time spent on smartphones is closely related to the severity of smartphone addiction(Lee, Ahn, Choi \& Choi, 2014; Lin et al., 2015).

This study was preliminary designed to develop a shortversion scale in order to evaluate the degree of addiction among medical student in Saudis Arabia as well as to suggest a cut-off value by gender using the previous scale and major concept of addiction for evaluation reference. In addition, characteristics of smartphone usage in participants are also investigated. The short-version scale developed from this study is expected to evaluate smartphone addiction in a simple and easy way, which will be less expensive and time consuming. The cut-off value can also be used in clinical and practical fields of society as well as other studies. The authors are expecting that this scale will be used efficiently for the screening of smartphone addiction in community areas and further studies, and for the evaluation of the treatment progress.

\section{Methodology}

\section{Study Design and Setting}

This was a cross-sectional study of all medical students from Saudi Arabian universities. These students were approached for the study from July 2016 to November 2016. We estimated the sample size to be at least 165 based on the calculation of five cases per item in the SAS (which has a total of 33 items). Therefore, a sample size of 243 in this study was adequate. Procedure.Stage 1: The author obtained the English version of the SAS from Kwon et al. Translation from English to Arabic was performed in parallel by two bilingual language experts, and a back translation was performed by a third bilingual language expert. 


\section{International Journal of Science and Research (IJSR) \\ ISSN (Online): 2319-7064}

Index Copernicus Value (2015): 78.96 | Impact Factor (2015): 6.391

Discrepancies between the original version and the back translation were discussed, and adjustments were made accordingly.

Stage 2: The finalized electronic version of the SAS was further reviewed by two consultant psychiatrists to assess the content and to ensure a satisfactory face and satisfactory semantics, criteria, and conceptual equivalence.

Stage 3: Information about the students' smartphone use based on their own estimation, such as the number of hours of use per week, the number of years as a regular smartphone user and the age at which they started to use a smartphone, were documented.

\section{Instruments}

Smartphone Addiction Scale. The SAS is a self-completed, 6-point Likert-type scale with 33 items. Each question has a response scale from 1 to $6(1=$ strongly disagree to to $6=$ strongly agree), reflecting the frequency of the symptoms. The respondent circles the statement that most closely describes their smartphone use characteristics. The total score possible on the SAS ranges from 48 to 288 . The higher the score is, the greater the degree of pathological use of the smartphone.

Internet Addiction Test. The IAT questionnaire, which was developed by Kimberly Young in 1998, is the tool most commonly used in diagnosing internet addiction. This is a self- completed questionnaire consisting of a 5-point Likerttype scale containing 20 items, with a minimum point value of 20 and a maximum point of value 100. The scoring of each question ranges from 1 to 5 ( $1=$ never to $5=$ always $)$, replicating the occurrence of the symptoms. The students chose the statement that best described the features of their internet use. The higher the score is, the greater the degree of pathological use of the internet is.

\section{Results}

There were 128 males and 115 females with ages ranging from 18 to 24 years old included in this study. Descriptive and factor analyses, intra-class coefficients, t-tests and correlation analyses were conducted to verify the reliability and validity of the SAS. The internal consistency and concurrent validity of the SAS-A were verified (Cronbach's alpha =.917). All of the subscales of the SAS-A. Demographic variables Usage in \%, age group 18-20s. Sex wise usage (average); Male is $52.9 \%$, Female is $47.1 \%$, total include in this study 243. Smartphone's global usage statistics by percentage of people using smartphones on the average day is 89 . Percentage of Smartphone's users Using for- "text messages" is 92. Percentage of Smartphone's users using it for "Internet browsing" is 84 . About 65 persons feel they use more than other. Social Media, calls, study accounts for $41.2 \%$. Visit psychiatry about $4.9 \%$ DAILY LIFE_M_CATG show moderate use of $48.6 \%$ (F: $39 \%$ M:61\%). OVERUSE_M_CATG is $54.3 \%$ (F: $46.2 \%$ M:53.8\%) Table 1
Table 1: General Characteristics

\begin{tabular}{|l|c|}
\hline Variables & Usage in \% \\
\hline Sex wise usage (average): & 52.7 \\
Male & 46.9 \\
Female & \\
\hline Devices in addition to the smartphone usage: & 4.1 \\
Desktop & 33.7 \\
Mobile & 9.5 \\
Tablet & 4.5 \\
Desktop, mobile & 1.2 \\
Desktop, tablet & 35.4 \\
Tablet, Mobile & 11.5 \\
Desktop, tablet, mobile & 100.0 \\
Total & 20.2 \\
\hline \% of smartphone usage during driving a car in \\
regular & \\
\hline Visit psychiatry about & 4.9 \\
\hline
\end{tabular}

\section{Conclusions}

This study developed the first smart phone addiction scale among medical students. This scale was shown to be reliable and valid.

\section{Discussion}

This study examined the internal consistency, dimensionality, and concurrent and construct validity of the SAS Arabic version. Findings from the study indicate that the SAS is a reliable and valid instrument for assessing smartphone addiction in the Arabic-speaking population. In this study, the SAS-A exhibited good internal consistency; Cronbach's alpha coefficient for the total scale was 0.917 .To date, this is the first study of its kind related to smartphone addiction, and it shows that the SAS-A is as good as the English version. However, the six dominant components that explained a large proportion of the variability of the SAS-A were similar to those of the original SAS.

Table 2: Internet Addiction Level

\begin{tabular}{|c|c|c|c|c|}
\hline & Frequency & Percent & $\begin{array}{c}\text { Valid } \\
\text { percent }\end{array}$ & $\begin{array}{c}\text { Cumulative } \\
\text { percent }\end{array}$ \\
\hline $\begin{array}{c}\text { Low level } \\
\text { of usage }\end{array}$ & 18 & 7.4 & 7.4 & 7.4 \\
\hline $\begin{array}{c}\text { Average } \\
\text { internet } \\
\text { user }\end{array}$ & 141 & 58.0 & 58.0 & 65.4 \\
\hline $\begin{array}{c}\text { frequent } \\
\text { problems } \\
\text { due to } \\
\text { internet } \\
\text { usage }\end{array}$ & 72 & 29.6 & 29.6 & 95.1 \\
\hline $\begin{array}{c}\text { Internet } \\
\text { usage } \\
\text { causes } \\
\text { significant } \\
\text { problem in } \\
\text { your life }\end{array}$ & 12 & 4.9 & 4.9 & 100.0 \\
\hline Total & 243 & 100.0 & 100.0 & \\
\hline
\end{tabular}

The components in the original SAS were "daily life disturbance", "positive anticipation", "withdrawal", "cyberspace-oriented relationship", "overuse" and "tolerance". All of the factors acquired in this factor analysis paralleled to the factors obtained in the original SAS. The meanings of the original SAS still the same during the

\section{Volume 6 Issue 1, January 2017 www.ijsr.net}




\section{International Journal of Science and Research (IJSR) \\ ISSN (Online): 2319-7064}

Index Copernicus Value (2015): 78.96 | Impact Factor (2015): 6.391

translation process. The majority of the components reported in the current study are the same. The background our study population was homogenous as all the subjects were medical students compared to the wide range of the occupation and education level in the original SAS study. The different interpretation could be complicated by the heterogeneity in the backgrounds and education of the studied population.

The prevalence of at-risk cases that could be identified as smartphone addiction using this scale was $29.6 \%$. There are several possible explanations for this result. The prevalence of smartphone addiction is expected as a local study has shown that $35.4 \%$ of Saudis own mobile phones and tablets. Smartphone provides free instant messaging through certain platforms, e.g., WhatsApp and WeChat, which enrich the lives of users.

Table 3: Usage of Smartphones among Medical Students Compared to those around them

\begin{tabular}{|c|c|c|c|c|}
\hline & Frequency & Percent & $\begin{array}{c}\text { Valid } \\
\text { Percent }\end{array}$ & $\begin{array}{c}\text { Cumulative } \\
\text { Percent }\end{array}$ \\
\hline Equal & 105 & 43.2 & 43.2 & 43.2 \\
\hline $\begin{array}{c}\text { Higher } \\
\text { than } \\
\text { average }\end{array}$ & 65 & 26.7 & 26.7 & 70 \\
\hline $\begin{array}{c}\text { I do not } \\
\text { know }\end{array}$ & 15 & 6.2 & 6.2 & 76.1 \\
\hline $\begin{array}{c}\text { I do not } \\
\text { know }\end{array}$ & 58 & 23.9 & 23.9 & \\
\hline Total & 243 & 100 & 100 & 100 \\
\hline
\end{tabular}

Entertainment is another possible explanation of the high prevalence of smartphone addiction because with these phones, medical students can listen to music, watch movies and play games to relieve stress. Therefore, they may tend to spend more time with their smartphone at the end of the day and to ultimately become pathological users.

By right the diagnosis of internet addiction should be based on three criteria as described by Ko, et al, 2012. SAS-A functions more like a screening or a scale for the assessment of the severity of addictive use of smartphone than a diagnostic instrument. Making a proper diagnosis of smartphone addiction will be an important issue for future research.

\section{Strength and Limitation}

The results of this study should be interpreted in the context of the study's limitations: First, there is no established diagnostic criterion for internet or smartphone addiction according to DSM V in the spectrum of addiction disorder $[21,25]$. However, in view of the limited studies in smartphone addiction in local setting, the results of this study still can give some insights to the health care professional team. Second, despite the sample size was adequate but it was not randomized. The gender and the race were not equally distributed. Moreover, this study was conducted at a single center, so the sample population was homogenous and may not reflect the general population of Saudi Arabia. Despite this limitation, the results of the present study proven that the SAS-A can be used for the evaluation of smartphone addiction among educated Saudi young adults.

\section{Conclusion}

This study developed the first smart phone addiction scale among medical students in Saudi Arabia. This study also provides evidence that the SAS-A is a valid and reliable, self-administered tool to screen for those at risk of having smartphone addiction.

\section{Abbreviation}

SAS $=$ Smart Phone Addiction Scale.

SAS-A = Smart Phone Addiction Scale Arabic version.

IAT $=$ Internet addiction test.

\section{Authors Contributions}

Alhassan, Alnofaily \& Alfayez participated in the study concept, literature review, Study design. Alfarhan \& Busaleh participated in data acquisition. Data analysis done by statics department of Dammam University, Saudi Arabia. Manuscript preparation done by Alhassan.

\section{References}

[1] Siew Mooi Ching1,2, Anne Yee3, Vasudevan Ramachandran, Sazlyna Mohd Sazlly Lim, Wan Aliaa Wan Sulaiman, Yoke. Loong Foo, Fan kee Hoo. Validation of a Malay Version of the Smartphone Addiction Scale among Medical Students in Malaysia; PLOS ONE DOI:10.1371/journal.pone.0139337; October 2, 2015; 15-20.

[2] Rashvand HF, Hsiao KF (2015) Smartphone intelligent applications: a brief review. Multimedia Systems 21(1):103119.

[3] Mosa AS, Yoo I, Sheets L (2012) A systematic review of healthcare applications for smartphones. BMC Medical Informatics and Decision Making 12: 67. doi: 10.1186/14726947-12-67 PMID: 22781312.

[4] Lane N, Mohammod M, Lin M, Yang X, Lu H, Ali S, et al. (2011) BeWell: A smartphone application to monitor, model and promote wellbeing. 5th International Conference on Pervasive Computing Technologies for Healthcare, Dublin.

[5] Patrick K, Griswold WG, Raab F, Intille SS (2008) Health and the mobile phone. American Journal of Preventive Medicine 35: 177-181. doi: 10.1016/j.amepre.2008.05.001 PMID: 18550322.

[6] Derbyshire E, Dancey D (2013) Smartphone Medical Applications for Women's Health: What Is the Evidence- Base and Feedback? International Journal of Telemedicine and Applications Article ID 782074, 10.

[7] Emad AS, Haddad E (2015) The Influence of Smart Phones on Human Health and Behavior: Jordanians' Perceptions. International Journal of Computer Networks and Applications 2 (2): 52-56.

[8] Sarwar M, Soomro TR (2013) Impact of Smartphone's on Society. European Journal of Scientific Research 98(2): 216226.

[9] Shin, Chloe Jihee;Yoon, Clara Sumin;Choi, Hun; A Study on Relation between Smartphone Addiction Factors and Gender: Focused on Adolescent International Information Institute (Tokyo). Information; Jun 2015; 18, 6(A); ProQuest SciTech Collection pg. 2233.

[10] Min Kwon1, Dai-Jin Kim2, Hyun Cho1, Soo Yang3*; The Smartphone Addiction Scale: Development and Validation of a Short Version for Adolescents; PLOS ONE | www.plosone.org; December 2013 | Volume 8 | Issue 12 | e83558. 